\title{
Lactose Absorption and Mucosal Disaccharidases in Convalescent Pellagra and Kwashiorkor Children
}

\author{
J. G. PRINSLOO, W. WITTMANN, H. KRUGER, and E. FREIER \\ From the National Institute for Nutritional Diseases, South African Medical Research Council, and the Department of \\ Paediatrics, Medical Faculty, University of Pretoria, Pretoria, South Africa
}

Prinsloo, J. G., Wittman, W., Kruger, H., and Freier, E. (1971). Archives of Disease in Childhood, 46, 474. Lactose absorption and mucosal disaccharidases in convalescent pellagra and kwashiorkor children. Oral lactose and glucose/galactose loading tests were done in Bantu children convalescing from kwashiorkor and pellagra. Small bowel biopsies and disaccharidase estimations were performed in all except 2 patients. Lactose absorption was more impaired and intestinal lactase levels were lower in the pellagra than in the kwashiorkor group. The fact that diarrhoea after admission to hospital was less common in pellagra than kwashiorkor was ascribed to a lesser lactose load due to the early introduction of a mixed diet in the former group, in comparison with milk feeds only in the latter group. The absence of troublesome diarrhoea while on moderate quantities of lactose in the diet, in the presence of low intestinal lactase levels, but evidence of lactose malabsorption after loading, has a bearing on preventive and therapeutic nutrition programmes in non-Caucasian children. Lactase deficiency is not necessarily synonymous with symptomatic lactose intolerance if the threshold is not exceeded. Concern is expressed that excessive caution against the use of milk may lead to a worsening of infantile malnutrition in developing countries.

During the past few years there have been several reports of lactose intolerance among non-Caucasian people (Cuatrecasas, Lockwood, and Caldwell, 1965; Cook and Kajubi, 1966; Bayless and Rosensweig, 1966; Davis and Bolin, 1967; Chung and McGill, 1968; Alzate, González, and Guzmán, 1969; Bayless and Huang, 1969; Haemmerli and Kistler, 1966; Jersky and Kinsley, 1967; Bolin, Crane, and Davis, 1968), and the possibility of either a genetic (Cook and Kajubi, 1966; Bayless and Rosensweig, 1966; Chung and McGill, 1968; Alzate et al., 1969; Bayless and Huang, 1969; Haemmerli and Kistler, 1966; Jersky and Kinsley, 1967), or an induced (Cuatrecasas et al., 1965; Davis and Bolin, 1967; Bolin et al., 1968; Bolin and Davis, 1970) deficiency due to lack of milk intake was raised. The practical significance of lactose intolerance in children suffering from proteincalorie malnutrition was indicated first by Dean (1957) and later by Bowie, Brinkman, and Hansen (1963, 1965). In our area kwashiorkor patients also had low intestinal lactase levels, though generally diarrhoea was not as severe as reported

Received 10 March 1971. from other centres (Prinsloo et al., 1969). The medical history of pellagra children revealed diarrhoea to be a complaint in about $16 \%$ of the patients (Prinsloo et al., 1968). However, from superficial judgement it does not appear to be a clinical problem after admission to hospital, even when milk forms part of their diet. This seems paradoxical, firstly in view of the reported high incidence of lactase deficiency in non-Caucasians, and secondly since diarrhoea is generally considered to be one of the main features of pellagra.

The patients with childhood pellagra seen by us do not as a rule appear severely ill and they have few if any systemic complaints. The serum albumin levels are usually lower than normal but not nearly as severely depressed as in kwashiorkor (Prinsloo et al., 1968). It therefore seemed possible that lactose tolerance could be less depressed in pellagra than in the more severely malnourished kwashiorkor patients. No published reports of intestinal lactase levels or lactose tolerance tests done on children suffering from pellagra could be found. It was therefore decided to evaluate lactose absorption and intestinal disaccharidase 


\section{Mucosal Disaccharidases in Convalescent Pellagra and Kwashiorkor Children}

levels of pellagra children and to compare the results with those obtained in kwashiorkor.

\section{Patients and Methods}

Bantu children recovering in hospital from typical kwashiorkor (10 patients) and classical pellagra without oedema (12 patients) were investigated. Patients who suffered from overt secondary infections as well were excluded. Oral lactose loads $(2.0 \mathrm{~g} / \mathrm{kg}$ body weight) and glucose/galactose $(1.0 \mathrm{~g} / \mathrm{kg}$ body weight of each) were administered during the convalescent phase. In 19 patients the tests were done within 3 weeks of admission to hospital and in 3 patients between 3 and 6 weeks after admission. An interval of 2 to 6 days separated the two sugar loads in order to allow possible diarrhoea caused by the sugar ingestion to subside. Capillary blood samples were collected in the fasting state and at half-hourly intervals for $1 \frac{1}{2}$ hours after the sugar loads. The blood glucose concentration was determined colorimetrically with the aid of the glucose oxidase method (C. F. Boehringer, Mannheim, Germany, test kit). The maximum blood glucose increment was calculated from the highest rise above the fasting level during the test (Haemmerli and Kistler, 1966). An attempt was made to classify patients into 'absorbers' and 'non-absorbers' according to their blood glucose increments after the sugar loads. The arbitrary dividing line used by different investigators varied (Welsh, Rohrer, and Walker, 1966; Chandra, Pawa, and Ghai, 1968; Bolin and Davis, 1970; Huang and Bayless, 1967; Bayless and Rosensweig, 1966; Dubois et al., 1970; Cook, 1967; Desai et al., 1970; Jussila, 1969). The majority, however, considered an increment in blood glucose concentration of more than $20 \mathrm{mg} / 100 \mathrm{ml}$ above the fasting level after a standardized oral sugar load as being indicative of 'absorption'. Thus patients who had a blood glucose rise of more than $20 \mathrm{mg} / 100 \mathrm{ml}$ above the fasting value at any stage during the test were designated 'absorbers' and those with lesser increments, 'non-absorbers'. Small bowel biopsies were also done during the convalescent phase in all except 2 patients. The biopsies were taken with a Watson infant-size capsule from the jejunum near the region of the ligament of Treitz after the capsule had traversed the duodenum. The position of the capsule was verified fluoroscopically with an image intensifier. The mucosal specimens were immediately weighed, frozen, and analysed for disaccharidases and protein content. Enzyme and protein estimations were done according to the methods of Dahlqvist (1964) and Lowry et al. (1951), respectively. Disaccharidase activities were expressed as units ( $\mu$ mole disaccharide hydrolysed per minute) per g protein.

The body weight of each patient was recorded on admission and expressed as a percentage of the 'expected' weight (Boston 50th centile-Nelson, 1964).

Statistical analysis. The blood sugar increments of the two groups after lactose as well as after glucose/ galactose loading were tested for significant differences by applying Wilcoxon-Mann-Whitney $U$ test (Siegel,
1956). The same test was used in the case of the disaccharidase and mucosal protein concentrations of the two groups. The two-tailed Wilcoxon matchedpairs signed-ranks test (Siegel, 1956) was used to test for a significant difference in blood sugar increments after lactose and glucose/galactose ingestion within the same group. In all tests a probability level of less than $5 \%(\mathrm{p}<0.05)$ was regarded as significant.

\section{Results}

The sex, age, body weight on admission, percentage expected weight of the patients, and the blood glucose increments after the sugar loads can be seen from the Table. The blood glucose increments after lactose were poor in both the pellagra and kwashiorkor groups, average peak levels being less than $25.0 \mathrm{mg} / 100 \mathrm{ml}$. The reponse of the pellagra group after lactose was less than that of the kwashiorkor group and the maximum increments of the 2 groups differed significantly $(p<0.01)$. The blood glucose increments of both groups after glucose/galactose intake were better than after lactose. Several patients, however, especially in the kwashiorkor group, still had unsatisfactory increments, but no significant difference was found between the values of the two groups $(p>0.05<0 \cdot 10)$. The maximum blood glucose increments of the kwashiorkor patients were similar both after lactose and after glucose/galactose and did not differ significantly. In the pellagra patients, however, the maximum increments after lactose were much less than after glucose/galactose, and the difference was highly significant $(\mathrm{p}<0.001)$.

After the lactose load there were no 'absorbers' in the pellagra group but 5 'absorbers' in the kwashiorkor group, whereas after glucose/galactose ingestion 9 of the 12 pellagra and 5 of the 10 kwashiorkor patients were 'absorbers'. Of the 5 kwashiorkor patients who were lactose 'absorbers', 2 failed to 'absorb' glucose/galactose. This is difficult to explain but might have been due to delayed gastric emptying in these 2 patients.

The intestinal disaccharidase levels, the sucrase/ lactase ratios, and the mucosal protein concentrations are also shown in the Table. The lactase concentrations of the pellagra patients were lower and their sucrase/lactase ratios higher than those of the kwashiorkor group. The difference between the values of the two groups was highly significant $(p<0.005)$ in the case of lactase concentrations, and significant $(p<0.02)$ in the case of the sucrase/ lactase ratios. There were no significant differences, however, between the sucrase, isomaltase, maltase, and mucosal protein concentrations of the two groups. 
Maximum Blood Glucose Increments of Patients $\overrightarrow{\vec{A}}$ fte

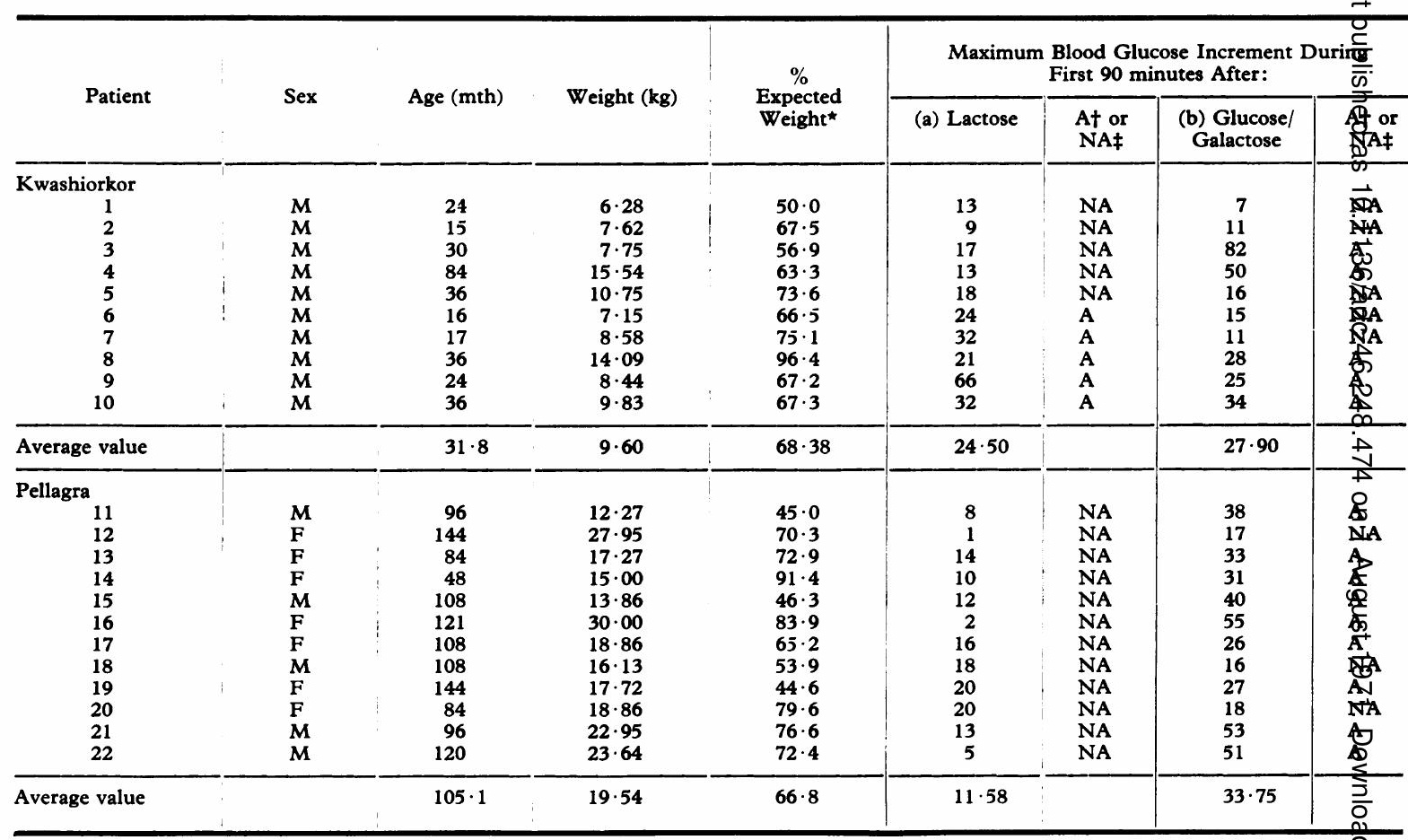

$\star$ Boston 50th centile. A† Absorber (see text). NA Non-absorber (see text)

$\S$ Units $=$ micromoles disaccharide hydrolysed $/ \mathrm{min} / \mathbf{g}$ 要

\section{Comments}

It can be seen from the Table that, in general, both groups of patients absorbed lactose poorly and that the pellagra group fared worse with a total absence of 'absorbers'. On the whole the pellagra group was able to absorb glucose/galactose better than lactose and also more efficiently than the kwashiorkor group, though the maximum increments of the two groups showed no significant differences. The greater inability of the pellegra patients in comparison with the kwashiorkor group to handle lactose is further evidenced by their blood glucose increments after lactose as well as their intestinal lactase levels. On both counts they had lesser average values than the kwashiorkor patients and the differences were significant. It is well known that blood glucose increments after loading tests may also be affected by the time of gastric emptying. It seems improbable, however, that the pellagra patients as a group could have had delayed absorption with lactose loading and not with glucose/galactose loading. Furthermore, considering a lactase level of over 10 units/g protein as normal (Dahlqvist, 1967), only 3 kwashiorkor patients had normal values while those of all the pellagra patients were abnormal. If the 3 normal values of the kwashiorkor group are excluded and the rest of the group is compared with the pellagra children, there is little difference in the lactase concentrations. It should be pointed out, however, that absolute enzyme values show great variations while the ratio of the different enzymes remain more or less constant in normal subjects (Prader and Auricchio, 1965). Thus the sucrase/lactase ratio has been considered a more reliable index, and a value of 4.0 or less suggested as normal (Prader and Auricchio, 1965; Welsh, 1968). Adopting this standard, all the patients except one were lactase deficient, and the pellagra group again had values furthest away from normal. The more severe lactase depression of the pellagra group was selective since the other disaccharidases did not differ significantly between the two groups.

These findings seem to be contradictory to our earlier remarks, namely that diarrhoea is neither a common complaint nor frequently encountered 
Caucasian children in developing countries (Bayless and Huang, 1969; McCracken, 1970) may lead to a worsening of the state of affairs. Lactose intolerance found after lactose loading need not in practice necessarily be symptomatic if the threshold is not exceeded. Desai et al. (1970) aptly pointed out that though diarrhoea developed in $62 \%$ of Indian subjects after a load of $50 \mathrm{~g}$ lactose, $90 \%$ of the population could tolerate at least $20 \mathrm{~g}$ lactose, the amount present in $450 \mathrm{ml}$ cows' milk.

We are indebted to Professor P. J. Pretorius, Head of the Department of Paediatrics, and to the Medical Superintendent of the H. F. Verwoerd Hospital for clinical facilities and permission to publish.

Correspondence to Dr. J. G. Prinsloo, Department of Paediatrics, Faculty of Medicine, P.O. Box 667, Pretoria, South Africa.

\section{REFERENCES}

Alzate, H., González, H., and Guzmán, J. (1969). Lactose intolerance in South American Indians. American fournal of Clinical Nutrition, 22, 122.

Bayless, T. M., and Huang, S. S. (1969). Inadequate intestinal digestion of lactose. American fournal of Clinical Nutrition, 22, 250.

Bayless, T. M., and Rosensweig, N. S. (1966). A racial difference in incidence of lactase deficiency. Fournal of the American Medical Association, 197, 968.

Bolin, T. D., Crane, G. G., and Davis, A. E. (1968). Lactose intolerance in various ethnic groups in South-East Asia. Australasian Annals of Medicine, 17, 300.

Bolin, T. D., and Davis, A. E. (1970). Primary lactase deficiency: genetic or acquired? American fournal of Digestive Diseases, $15,679$.

Bowie, M. D., Brinkman, G. L., and Hansen, J. D. L. (1963). Diarrhoea in protein-calorie malnutrition. Lancet, 2, 550.

Bowie, M. D., Brinkman, G. L., and Hansen, J. D. L. (1965). Acquired disaccharide intolerance in malnutrition. Fournal of Pediatrics, 66, 1083.

Chandra, R. K., Pawa, R. R., and Ghai, O. P. (1968). Sugar intolerance in malnourished infants and children. British Medical fournal, 4, 611.

Chung, M. H., and McGill, D. B. (1968). Lactase deficiency in Orientals. Gastroenterology, 54, 225.

Cook, G. C. (1967). Lactase activity in newborn and infant Baganda. British Medical fournal, 1, 527.
Cook, G. C., and Kajubi, S. K. (1966). Tribal incidence of lactase deficiency in Uganda. Lancet, 1, 725.

Cuatrecasas, P., Lockwood, D. H., and Caldwell, J. R. (1965). Lactase deficiency in the adult: a common occurrence. Lancet, $1,14$.

Dahlquist, A. (1964). Method for assay of intestinal disaccharidases Analytical Biochemistry, 7, 18.

Dahlqvist, A. (1967). Intestinal disaccharidases and disaccharide intolerance. Acta Vitaminologica et Enzymologica, 21, 93.

Davis, A. E., and Bolin, T. (1967). Lactose intolerance in Asians. Nature (London), 216, 1244.

Dean, R. F. A. (1957). Digestion in kwashiorkor. Moderne Probleme der Pädiatrie, 2, 133.

Desai, H. G., Gupte, U. V., Pradhan, A. G., Thakkar, K. D., and Antia, F. P. (1970). Incidence of lactase deficiency in control subjects from India. Indian fournal of Medical Sciences, 24, 729.

Dubois, R. S., Roy, C. C., Fulginiti, V. A., Merrill, D. A., and Murray, R. L. (1970). Disaccharidase deficiency in children with immunologic deficits. Fournal of Pediatrics, 76, 377.

Haemmerli, U. P., and Kistler, H. (1966). Disaccharide malabsorption. In Disease a-Month. Year Book Medical Publishers, Chicago.

Huang, S. S., and Bayless, T. M. (1967). Lactose intolerance in healthy children. New England fournal of Medicine, 276, 1283.

Jersky, J., and Kinsley, R. H. (1967). Lactase deficiency in the South African Bantu. South African Medical fournal, 41, 1194.

Jussila, J. (1969). Milk intolerance and lactose malabsorption in hospital patients and young servicemen in Finland. Annals of Clinical Research, 1, 199.

Lowry, O. H., Rosebrough, N. J., Farr, A. L., and Randall, R. J. (1951). Protein measurement with the Folin phenol reagent. Fournal of Biological Chemistry, 193, 265.

McCracken, R. D. (1970). Adult lactose tolerance. Fournal of the American Medical Association, 213, 2257.

Nelson, W. E. (1964). Textbook of Pediatrics, 8th ed., p. 48. Saunders, Philadelphia and London.

Prader, A., and Auricchio, S. (1965). Defects of intestinal disaccharide absorption. Annual Review of Medicine, 16, 345.

Prinsloo, J. G., Du Plessis, J. P., Kruger, H., De Lange, D. J., and De Villiers, L. S. (1968). Protein nutrition status in childhood pellagra. American fournal of Clinical Nutrition, 21, 98.

Prinsloo, J. G., Wittmann, W., Pretorius, P. J., Kruger, H., and Fellingham, S. A. (1969). Effect of different sugars on diarrhoea of acute kwashiorkor. Archives of Disease in Childhood, 44, 593.

Siegel, S. (1956). Nonparametric Statistics for the Behavioral Sciences, p. 116. McGraw-Hill, New York.

Welsh, J. D. (1968). Primary and secondary disaccharide malabsorption. Internal Medicine Digest, 3, 23.

Welsh, J. D., Rohrer, G. V., and Walker, A. (1966). Human intestinal disaccharidase activity. Archives of Internal Medicine, 117, 488. 